\title{
Opinión pública y ciberespacio: una reflexión sobre sus potencialidades y límites
}

\author{
Edwin Cruz Rodríguez* \\ (ecruzr@unal.edu.co)
}

Artículo de investigación recibido el 29/11/2014 y aprobado el 20/04/2015

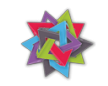

Cómo citar este artículo:

CRUZ RODRÍGUEZ, Edwin (2015). “Opinión pública y ciberespacio: una reflexión sobre sus potencialidades y límites”. En: Trans-pasando Fronteras, núm. 7, pp. 107-124. Cali, Colombia: Centro de Estudios Interdisciplinarios, Jurídicos, Sociales y Humanistas (CIES), Facultad de Derecho y Ciencias sociales, Universidad Icesi.

DOI: $10.18046 /$ retf.i7.1787

\section{Resumen}

Este artículo estudia la incidencia de Internet sobre la esfera pública y la opinión pública tomando como referencia las conceptualizaciones más aceptadas de lo público y la opinión pública. La primera parte reconstruye de modo sumario los conceptos de lo público, la esfera pública y la ciudadanía; sobre el trasfondo de esas categorías, la segunda parte formula las potencialidades y limitaciones de la World Wide Web respecto a lo público y la esfera pública en general y la opinión pública en particular. Si bien Internet posibilita una mayor igualdad y una comunicación más horizontal entre las personas conectadas, no implica un cambio sustancial con las formas de funcionamiento de la esfera pública, caracterizadas

* Politólogo de la Universidad Nacional de Colombia. Actualmente cursa doctorado en Estudios políticos en la misma universidad. Sus áreas de interés son la acción colectiva y los movimientos sociales, el pensamiento político latinoamericano y la historia conceptual de lo político. Recientemente publicó "Pensar la interculturalidad. Una invitación desde Abya-Yala/América Latina (Quito, Abya-Yala, 2013)". 
por la competencia y el conflicto por constituir la opinión pública.

\section{Palabras clave}

Internet, ciberespacio, World Wide Web, público, esfera pública, opinión pública.

\section{Introducción}

Quizás el medio de comunicación que más ha ganado protagonismo como espacio donde se construye la "opinión pública" es Internet. Hoy existen muy pocas opiniones, con legitimidad para reclamarse como parte de la "opinión pública", que no pasen por convertirse primero en "tendencia" en el mundo virtual, siendo más visitadas, más retuiteadas o más compartidas, mediante la diversidad de mecanismos que permiten transmitir información entre los ordenadores y sus usuarios. En efecto, convertir algún tipo de información en "tendencia" es una creciente preocupación para quienes diseñan los sondeos de mercadeo y publicidad o formulan las estrategias de las campañas electorales.

Tal vez resulte exagerado afirmar que el ciberespacio empieza a predominar sobre o a reemplazar los espacios de interacción social del mundo "real", sobre todo si se tiene en cuenta que la conectividad no es homogénea, pues en materia de acceso a Internet existen enormes diferencias entre países situados en distintas partes del Planeta y, en el interior de éstos, entre estratos, clases sociales, o regiones. Además, la World Wide Web es apenas uno más de los medios de comunicación de los que, al menos desde hace tres siglos, se han valido los ciudadanos para expresar sus opiniones en público y la forma como incida en los espacios de sociabilidad "reales" depende en buena medida de sus contextos particulares. Sin embargo, la incidencia de Internet en la configuración de la opinión pública ha llegado hasta el punto de que muchos diarios impresos, que desde el ascenso del "capitalismo de imprenta" a mediados del siglo XVIII constituyeron uno de los foros privilegiados para formar opinión, han decidido concentrar sus esfuerzos en sus portales web e incluso llegando a suspender sus ediciones impresas.

Todo ello plantea la necesidad de preguntarnos ¿qué consecuencias tiene Internet respecto de la formación de la opinión pública?, ¿es el ciberespacio una esfera pública más abierta o menos excluyente que la esfera pública "real"?, ¿cuáles son las ventajas y desventajas del mundo 2.0 de cara a la formación de la opinión pública? 
Éste ensayo aborda estos interrogantes mediante un análisis de las potencialidades y los límites de Internet como esfera pública, basado en las conceptualizaciones más aceptadas de lo público y la opinión pública. La primera parte reconstruye de modo sumario los conceptos de lo público, la esfera pública y la ciudadanía; sobre el trasfondo de esas categorías, la segunda parte formula las potencialidades y limitaciones de la World Wide Web respecto a lo público y la esfera pública en general y la opinión pública en particular. Si bien Internet posibilita una mayor igualdad y una comunicación más horizontal entre las personas conectadas, no implica un cambio sustancial con las formas de funcionamiento de la esfera pública, caracterizadas por la competencia y el conflicto por constituir la opinión pública.

\section{Lo público, la esfera pública y la opinión pública}

Si bien las conceptualizaciones sobre lo público han logrado emancipar esta categoría de su referencia predominante al Estado, desde una perspectiva analítica aún es necesario diferenciar distintos fenómenos estrechamente ligados pero que presentan una especificidad, tales como los de esfera pública y opinión pública. Así, lo público hace referencia a lo visible, admisible y enunciable, por contraposición a aquello que no lo es y que por tanto se reserva al ámbito de lo privado. La esfera pública no sólo designa las condiciones de visibilidad, admisibilidad y enunciabilidad, sino un espacio institucionalizado de participación ciudadana. Finalmente, la opinión pública hace referencia al resultado de la confluencia, no siempre consensual, de distintas opiniones privadas en el ámbito de la esfera pública, en la búsqueda de definir el interés común.

\section{Lo público}

Como es bien sabido, lo público no puede entenderse sino por referencia a lo privado. Por esa razón, Bobbio (2006: 11-38) considera estas categorías como la "gran dicotomía" del pensamiento político. Se trata de "un par de conceptos que se caracterizan por ser relacionales y antónimos: cada uno se define en relación y en oposición al otro: lo que no es público es privado y viceversa" (Sánchez, 2003: 243). Esa dicotomía nace en la modernidad occidental, en el proceso de formación del Estado, aunque lo público no se reduce a él, y sobre todo se desarrolla en el ámbito jurídico. 
Precisamente, desde la perspectiva de la teoría del derecho, Bobbio (2006: 15-18), caracteriza ambas esferas. En este registro, lo público ha sido entendido como el Estado, las instituciones y la colectividad en general, y lo privado como lo perteneciente a los miembros específicos o los grupos menores, como la familia y las relaciones entre los particulares. Esta gran dicotomía se estructura a su vez en otras: (1) la sociedad de desiguales, es decir, el Estado y sus súbditos, entendida como lo público, versus la sociedad de iguales en el mercado; (2) la ley, como forma de regulación jurídica que se deriva de la autoridad pública, se fundamenta en pretensiones de generalidad (asuntos comunes al conjunto de la sociedad) y universalidad (obliga a todos) versus el contrato, como un acuerdo de particulares en el marco de la ley pero fuera de su generalidad y universalidad; y finalmente (3), la justicia conmutativa, que corresponde a la lógica privada del intercambio, la remuneración en función del principio de equivalencia entre las partes, versus la justicia distributiva, una lógica de compensación utilizada por la autoridad pública, de acuerdo con el mérito, la necesidad, el trabajo, entre otros.

En un sentido similar, para Nora Rabotnikof (1997: 136), en la experiencia histórica occidental pueden encontrarse al menos tres concepciones de la dicotomía: primero, lo público como lo atinente a lo colectivo versus lo atinente a lo individual, que evoluciona en el campo jurídico a la dicotomía entre lo político-estatal y lo civil; segundo, la metáfora del "espacio público", que ubica lo público en algún lugar entre la esfera del Estado y la sociedad o entre esferas de acción distintas, como lo cerrado versus lo accesible, y tercero, la esfera pública como un espacio de comunicación abierta: lo transparente versus lo secreto.

Así pues, en su sentido más básico, lo público tiene dos atributos. De una parte, remite a aquello que es manifiesto o realizado frente a unos espectadores (vale decir, un público), que se distingue de lo que se realiza en privado, en un círculo reducido de personas o, incluso, en secreto (Bobbio, 2006: 17). En este sentido, el carácter público de un espacio está definido en virtud de las posibilidades de visibilidad frente a los espectadores, mientras más visible sea algo, más público será, frente a lo privado, esto es, lo que se considera invisible, inadmisible o no enunciable para ser considerado en presencia de los demás (Lozano, 2005: 30-56). Por consiguiente, la publicidad hace referencia al grado en que un entramado de relaciones sociales permite hacer visible, admisible o enunciable. 
Por otro lado, lo público también se define por aquello que es "propiedad de todos", si entendemos "propiedad" en sentido amplio, frente a lo privado que es de uso exclusivo y restringido, o como un espacio "abierto virtualmente a todos" frente a un espacio exclusivo (Varela, 2005: 25). Como sostiene Hannah Arendt (1996: 56, 61), lo público es aquello que es común a todos:

\begin{abstract}
La palabra público significa dos fenómenos estrechamente relacionados, si bien no idénticos por completo. En primer lugar significa que todo lo que aparece en público puede verlo y oirlo todo el mundo y tiene la más amplia publicidad posible. [...] En segundo lugar, el término público significa el propio mundo, en cuanto es común a todos nosotros y diferenciado de nuestro lugar poseido privadamente en él.
\end{abstract}

Bajo estas categorías, Internet aparece como un espacio público por excelencia, en la medida en que posibilita una igualdad de condiciones, el libre acceso individual y un gran nivel de publicidad (de hecho, los problemas radican más bien en restringir la libertad cuando lo que se hace visible vulnera derechos).

\title{
La esfera pública
}

Por otra parte, más allá del mero hecho de la publicidad, lo público está necesariamente ligado a lo político, bajo la forma de una esfera pública institucionalizada donde se adoptan decisiones vinculantes. Por ejemplo, siguiendo con la aproximación de Arendt (1996) a la antigüedad clásica, en la ciudad-Estado griega lo público estaba caracterizado como la esfera de la polis y de las actividades libres relacionadas con ese mundo común que los ciudadanos construían. Lo privado, por su parte, hacía referencia a la esfera de las necesidades, compuesta por la familia y las actividades relativas a la satisfacción de las mismas. Por eso, en lo privado tienen lugar la labor y el trabajo, mientras lo público es del dominio de la vida activa, la política. Lo público se constituye así como una esfera de libertad a la que sólo acceden quienes tengan el estatus de ciudadano, es decir, aquellos que: (1) tienen resueltas sus necesidades y (2) por ello no dependen de nadie.

En la antigüedad, como es bien sabido, la ciudadanía estuvo restringida a los "padres de familia" en virtud de esos criterios. Sin embargo, en la modernidad la razón 
de ser de las comunidades políticas fue incluir bajo el estatus de ciudadanos a todos sus miembros. De esa forma, como advirtió el clásico estudio de Thomas H. Marshall (1997), la ciudadanía designa una igualdad humana básica determinada por la pertenencia a una comunidad política. El estatus de la ciudadanía es compatible con todo tipo de desigualdades que existen en la sociedad y en primer lugar con la desigualdad socioeconómica de clase. Constituye una igualdad frente a la comunidad política, al Estado, aunque no una igualdad total, y está mediada por el reconocimiento de derechos y la participación política.

Así pues, la implicación de ciudadanos en los asuntos políticos no puede desligarse de la emergencia de la esfera pública. A este respecto, Habermas (1982: 68) estudia la configuración de la esfera pública burguesa durante el proceso de formación de los Estados absolutistas en el siglo XVIII, especialmente los casos de Inglaterra, Francia y Alemania. Para el filósofo alemán, la esfera pública burguesa es producto de la pretensión de la burguesía en ascenso de incidir en la toma de decisiones políticas y corresponde a un espacio abierto de discusión racional. Es situada por Habermas en un lugar intermedio entre la esfera del poder político, donde se ubica el Estado, y el ámbito privado, donde se sitúa el tráfico mercantil y el espacio familiar. Se trata, entonces, de una esfera intermedia entre el ámbito privado (familia, tráfico mercantil y trabajo social) y la esfera del poder público, la Corte y el Estado.

\section{La opinión pública}

Es en este espacio donde se forma la opinión pública, allí se comunican los discursos elaborados en el ámbito de lo privado y se pretende, mediante la deliberación basada en la razón, producir un consenso sobre el interés común, que permita al mismo tiempo controlar a las burocracias estatales y retroalimentar al Estado. En ese espacio, además de la deliberación racional entre sujetos privados, se da un intercambio comunicativo en la prensa, en los libros académicos o en los medios de comunicación, con base en el supuesto de igualdad formal del ciudadano liberal y con el propósito de permitir una comunicación fluida entre el ámbito de lo privado y el Estado. En síntesis, la opinión pública, desde la perspectiva habermasiana, es el resultado de la deliberación racional sobre el interés común en un espacio no excluyente basado en la igualdad de condiciones para participar. La opinión pública es un consenso racional sobre el bien común (Fraser, 1997: 100). 
Sin embargo, como también advierte Fraser (1997: 99), ese modelo idealizado de esfera pública liberal planteado por Habermas tiene unos supuestos problemáticos: se asume que es abierta y al alcance de todos, los intereses privados no son admisibles, la desigualdad es puesta entre paréntesis o suspendida y el poder es excluido para posibilitar la deliberación entre pares. En contraste, y apoyada por una revisión historiográfica, la filósofa norteamericana (Fraser, 1997: 107-108) desarrolla cuatro críticas contundentes al enfoque habermasiano:

En primer lugar, sostiene que el supuesto según el cual los interlocutores pueden poner entre paréntesis sus diferencias de posición y deliberar "como si" fueran iguales, supone que la igualdad social no es condición necesaria para la democracia política; al velar las desigualdades reales suponiendo que en la "esfera pública" los individuos son iguales y tienen igual estatus para participar, termina por sancionar las desigualdades reales en lugar de someterlas a discusión. Segundo, Fraser objeta un supuesto presente en la argumentación de Habermas según el cual es preferible una esfera pública única, en lugar de públicos diversos. Para Fraser, ello implica a una exclusión de voces que pueden hacerse oír en esferas públicas distintas a la burguesa que estudia Habermas. En tercer lugar, para Fraser resulta inaceptable el hecho de que el discurso en el espacio público deba restringirse a la deliberación sobre el bien común, así como el que el surgimiento de intereses y asuntos privados se considere siempre indeseable, pues a su juicio el punto de partida para la deliberación es definir aquello que se entiende por lo público y lo privado. Finalmente, para la filósofa norteamericana resulta problemático el supuesto de distinción tajante entre sociedad civil y Estado, puesto que de esa forma se sanciona también la existencia de públicos fuertes, aquellos que pueden adoptar decisiones vinculantes, y públicos débiles, los que no pueden hacerlo.

Estas objeciones implican de fondo que en la esfera pública es prácticamente muy difícil llegar a un consenso racional sobre el bien común, u opinión pública. En consecuencia, ésta será producto de una lógica de discusión marcada por el conflicto y la competencia entre distintas visiones particulares del bien común.

\section{Límites y potencialidades}

¿La tecnología de Internet modifica sustancialmente el desempeño de la esfera pública y la producción de la opinión pública? En un sugestivo ejercicio de análisis, Tilly y Wood 
(2008: 210), constatan que en el siglo XXI se ha incrementado el uso de las nuevas tecnologías de la comunicación, principalmente Internet, pero al mismo tiempo hacen un llamado a evitar el "determinismo tecnológico":

\begin{abstract}
Debemos andarnos con pies de plomo antes de decantarnos por el determinismo en las comunicaciones, tanto en un sentido genérico como en otro más concreto: en un sentido genérico, suponiendo que cada una de estas innovaciones ha transformado por sí misma la vida social y la acción política; en un sentido concreto, imaginando que Internet y los teléfonos móviles nos brindan un poder de comunicación tan grande que alejan a la gente de las relaciones y las prácticas sociales previamente existentes. (Tilly y Wood, 2008: 202).
\end{abstract}

Aplicado a nuestro problema, esta advertencia se traduce en una respuesta matizada a la pregunta formulada. En términos de accesibilidad, si bien el ciberespacio ofrece oportunidades impensadas de intervención en la esfera pública, depende del grado de conectividad, por lo que en la práctica mantiene las restricciones y exclusiones que caracterizan la esfera pública. Respecto de la deliberación, si bien Internet posibilita una comunicación más dialógica que otros medios de comunicación y puede ser aprovechado por contrapúblicos, no implica un avance sustancial respecto de las lógicas de producción de la opinión pública que predominan en el "mundo real". En fin, Internet ha llegado a amenazar la esfera de lo privado y de lo íntimo.

\title{
Accesibilidad
}

A fines del siglo XVIII y comienzos del XIX, cuando tiene lugar la formación de la esfera pública burguesa estudiada por Habermas, la igualdad no se entendió tanto como igualdad de oportunidades o igualdad en el terreno económico sino como homogeneidad. Para pertenecer a la comunidad política y participar en la esfera pública era necesario ser ciudadano con todas las consecuencias que ello conlleva en ese momento en términos de género, clase y raza (Wills, 2005). Como anteriormente se mencionó, en su concepción estrictamente liberal la ciudadanía es el concepto que unifica a los individuos particulares en su relación con el Estado y proporciona un criterio de homogeneidad que permite ignorar o suspender las desigualdades (eco- 
nómicas, culturales, religiosas y de género) que persisten entre los individuos. Esas desigualdades son relegadas al espacio de lo privado. Se supone que en el espacio público todos somos iguales en tanto ciudadanos a pesar de nuestras desigualdades en lo privado. En lo privado se puede adoptar una identidad particular, mujer, homosexual, indígena o mormón, pero en lo público se adquiere el estatus de ciudadano igual al resto con los mismos derechos.

Esa escisión impuso límites al acceso igualitario a al esfera pública. Para Fraser (1997: 110-113), la plena accesibilidad a la esfera pública liberal que reivindica Habermas no se consiguió, puesto que en la práctica fueron excluidos las mujeres, los pobres y los no blancos de la posibilidad de hacer escuchar su voz, ya fuese por prejuicios culturales (machismo, racismo) o por no poder disponer de los capitales sociales y culturales (saber leer y escribir, disponer determinada renta o propiedad). Al suponer que existía igualdad social, lo que se hizo fue sancionar esa desigualdad, desconociéndola. La deliberación, que pretendió ser entre "iguales", de esa forma terminó por encubrir la dominación, lo cual puso en ventaja a los grupos sociales dominantes.

Respecto a esta problemática de la accesibilidad, Internet presenta un carácter ambiguo. Por una parte, si el mundo 2.0 se asume como un espacio público, resulta ser más incluyente e igualitario que otros medios de comunicación. Como alguna vez lo dijera Bill Gates, "una de las cosas más maravillosas de la autopista informática es que la equidad virtual es más fácil de alcanzar que la equidad real... Todos somos creados iguales en el mundo virtual" (Negri y Hardt, 2001: 299).

En efecto, en el ciberespacio los usuarios aparecen como "iguales", todos los individuos tienen el mismo estatus anónimo. Pero, además, a diferencia de la esfera pública moderna excluyente de lo diverso, los usuarios de internet tienen la posibilidad de manifestar su diferencia si así lo consideran. En otras palabras, en el espacio abierto de Internet los individuos tienen las mismas posibilidades de hacerse oír y, además, de poner en discusión esas diferencias de género/sexo, clase, o étnicas, entre otras, que la esfera pública liberal relegó al espacio de lo privado. Finalmente, internet brinda la posibilidad de intercambiar opiniones y de coordinar deliberaciones a grandes distancias, más allá de la comunidad de pertenencia de los usuarios. 
No obstante, al examinar la situación fuera del mundo virtual, las condiciones de accesibilidad aparecen profundamente desiguales. Obviamente, las anteriores ventajas del Internet operan solamente para las personas que tienen acceso a la red, y como se afirmaba anteriormente, la conectividad sigue siendo desigual en el planeta.

Como sugieren Tilly y Wood (2008: 204) "cada nueva forma de contacto posible gracias a las comunicaciones facilita un conjunto específico de relaciones sociales al tiempo que excluye a otras personas, aquellas que no tienen acceso a la tecnología en cuestión". Por consiguiente, fuera del ciberespacio se mantienen las restricciones de accesibilidad a la esfera pública. Tales restricciones no sólo se explican porque no existan las posibilidades reales de conectarse, que podrían implicar la exclusión de ciertos espacios o regiones, por ejemplo, siempre los individuos residentes en países desarrollados tendrán más oportunidades de acceso; o por falta de recursos económicos o culturales para hacerlo, lo que se traduce en exclusión basada en criterios de clase. El denominado "analfabetismo digital", la carencia del conocimiento técnico para interactuar a través de un ordenador funciona como una barrera de acceso. También puede suponer exclusiones de sexo/género o de raza/etnia, si se tiene en cuenta que en las sociedades patriarcales y racistas o excluyentes, las personas situadas en los estratos sociales más bajos pertenecen a estas categorías.

\section{Deliberación}

A diferencia de los medios de comunicación basados en una relación unidireccional entre el emisor y el receptor mediada por un código y un mensaje que permanece intacto mientras se realiza la comunicación, Internet introduce la posibilidad de la interacción.

Jesús Martín-Barbero (1988) llamó la atención sobre la forma distorsionada de concebir la comunicación como un acto unidireccional en el que quien controlase el medio y el código podría controlar el acto comunicativo; a su juicio, toda comunicación estaba mediada por una determinada "matríz cultural" que resignificaba los mensajes en el momento en que estos llegaban al receptor. No obstante, internet plantea una forma de comunicación que rompe con el modelo emisor-receptor. Así, a diferencia de la radio o la televisión, caracterizadas por un centro emisor que tiene potestad 
sobre el mensaje, Internet hace posible la interacción. Como sostienen Tilly y Wood (2008: 204), se trata de una forma de comunicación más simétrica:
[...] los medios de comunicación varían poderosamente en su grado de simetría
y asimetría: los periódicos, la radio y la televisión reflejan una relación entre sus participantes extraordinariamente asimétrica, pues son pocos los produc- tores y muchos los consumidores, mientras que las comunicaciones digitales recomponen ese equilibrio en la medida de lo posible

Así, mientras la esfera pública burguesa se estructuró mediante la interacción a través de medios de comunicación como la prensa escrita, basada en forma preponderante en el modelo emisor-receptor, los usuarios de internet tienen la posibilidad de interactuar con otros usuarios y en muchos casos de deliberar, como lo supone el modelo liberal o habermasiano de esfera pública.

Ahora bien, la facilidad con que pueden discurrir e interactuar los discursos en Internet se ve contrarrestada por las lógicas de mercado, las lógicas de censura y control que también operan y la carencia de deberes o, cuando menos, de compromiso de los usuarios.

En primer lugar, en el posicionamiento de las "tendencias" en internet, así como en la creación de seguidores y audiencias para un determinado mensaje, operan mecanismos de mercado similares a los que se ponen en práctica para medios de comunicación como la radio y la televisión. En este sentido, operan formas de medición que comprenden el número de visitas de un website, el número de lecturas, el número de seguidores o de "me gusta", los cuales dependen de estrategias de mercadeo que empiezan por la publicidad en sitios más visitados o por el uso de otros medios, como la radio o la televisión.

Así, si bien potencialmente todos los usuarios tienen la misma posibilidad de expresarse y poner a circular su punto de vista, en la práctica el grado en que su opinión consiga ser escuchada depende de la cantidad de recursos que el usuario tenga a su disposición para promocionar su mensaje. De esta forma, la libertad de expresión tiende a convertirse más en un privilegio, al que acceden quienes disponen de la capacidad para implementar distintas estrategias de mercadeo, que en un derecho igualitario. Por ejemplo, no es igual expresar opiniones en un blog que no es visitado que publicarlas 
en una página que determina "tendencias". Ello pone en evidencia que en internet también existen monopolios y oligopolios.

Segundo, la posibilidad potencial que tienen los usuarios para manifestar sus opiniones en Internet se ven truncadas por aquello que Manuel Castells (2001: 196) denominó las "tecnologías de control", mecanismos de censura que se despliegan en cada página web, o bien en un espacio territorial determinado.

Finalmente, aunque el carácter igualitario y muchas veces anónimo del usuario genera una situación de igualdad, también puede conducir a la ausencia de compromiso a la hora de deliberar. Una de las quejas más recurrentes de los usuarios de redes sociales como Facebook o Twitter es el bajo nivel de la argumentación, cuando no la irresponsabilidad de quienes intervienen en debates.

De todo ello se infiere que el ciberespacio no implica un avance respecto a las lógicas que priman en las deliberaciones que se producen en la esfera pública "real". Esta conclusión no es ninguna novedad para una autora como Nancy Fraser (1997), quien arguye que, lejos del supuesto de neutralidad y equidad en que se funda la deliberación habermasiana, existen lógicas de poder y de hegemonía que en última instancia son las que terminan por producir eso que llamamos la opinión pública. En otras palabras, ésta no es producto de un consenso racional sobre el bien común, sino producto de una hegemonía. De acuerdo con Fraser (1997: 98), Habermas limitó su estudio al surgimiento de la esfera pública burguesa, basado en un modelo normativo liberal de esfera pública, lo que llevó a descuidar los desarrollos que podrían tener otros modelos de esfera pública, no burgueses o postburgueses. Desde su perspectiva, no existe solamente una esfera pública, sino un conjunto de esferas públicas en competencia por determinar lo que constituye el bien común, la opinión pública. Entre esas esferas públicas plurales están comprendidas aquellas que denomina los "contrapúblicos subalternos". Como ella misma explica,

Los miembros de los grupos sociales subordinados -mujeres, trabajadores, personas de color, gays y lesbianas- han comprobado repetidamente que resulta ventajoso construir públicos alternativos. Propongo llamar a estos públicos contra públicos subalternos para indicar que se trata de espacios discursivos paralelos donde los miembros de los grupos sociales subordinados inventan y 
hacen circular contra-discursos, lo que a su vez les permite formular interpretaciones opuestas de sus identidades, intereses y necesidades. Quizás el ejemplo más impresionante sea el contra-público subalterno feminista de finales del siglo veinte en los Estados Unidos, con su abigarrado conjunto de revistas, librerías, editoriales, redes de distribución de películas y videos, series de conferencias, centros de investigación, programas académicos, congresos, convenciones, festivales y lugares de reunión locales. En esta esfera pública, las feministas han inventado nuevos términos para describir la realidad social. Incluyendo "sexismo", "doble jornada", "acoso sexual" y "violación intramarital", "en una olla" (date rape) y "por un conocido" (acquaince rape). Armadas con este lenguaje, hemos formulado de nuevo nuestras necesidades e identidades y, al hacerlo, hemos reducido, aunque no eliminado, nuestra desventaja en la esfera pública oficial (Fraser, 1997: 115).

En últimas, si bien en Internet se reproducen los mismos problemas de la esfera pública "real", no puede desconocerse que ha potenciado la aparición de contrapúblicos subalternos que muchas veces se extienden más allá de las fronteras que hubiesen posibilitado otros medios de comunicación y hacen posible circular contradiscursos, opiniones no hegemónicas, en distintos temas.

\section{¿Y lo privado?}

Como anteriormente se mencionó, lo público no puede definirse sino en correspondencia con lo privado. A condición de hacer admisibles aspectos privados e incluso íntimos que la esfera pública burguesa expulsó de lo público y relegó al ámbito de lo privado, internet promueve una creciente erosión de los límites entre lo público, lo privado y lo íntimo. Expertos como Manuel Castells (2001: 198-201), han llegado a plantear como consecuencia "el fin de la privacidad".

En la crítica que Fraser formula a Habermas destaca el hecho de que la deliberación sobre lo común no puede tener como punto de partida o a priori una concepción determinada de lo común y, por consiguiente, que las concepciones de lo que es público y lo que es privado deben ser consecuencia de la deliberación y no un supuesto de partida. Sólo los participantes pueden decir qué constituye un interés común para ellos, pero eso no significa que lo logren. No hay fronteras naturales dadas a priori, lo público se define 
mediante una confrontación discursiva. Ningún tema puede ser excluido previamente, las minorías deben tener la oportunidad de convertir sus asuntos de interés común. Fraser (1997: 123), lo plantea de la siguiente manera:

\begin{abstract}
El punto es que, a este respecto, no existen fronteras naturales dadas a priori. Lo que debe considerarse como un asunto de interés común será decidido, precisamente a través de la confrontación discursiva. De lo anterior se sigue que ningún tópico debe ser excluido previamente a tal confrontación. Por el contrario, la publicidad democrática exige garantías positivas de oportunidad para que las minorías puedan convencer a otros de aquello que en el pasado no era público, en el sentido de no ser de interés común, deberá serlo ahora.
\end{abstract}

En suma, la definición de lo que se considera público y lo que se considera privado está sujeta a la misma competencia y al conflicto por producir la opinión pública. Este problema se complica en el ciberespacio. Si bien lo usuarios de Internet tienen una igualdad básica como usuarios anónimos, también es cierto que no existe prácticamente nada que pueda ocultarse. Es cierto que no por ello todo es público, en la medida en que no es visible para "todos", pero lo cierto es que ha dejado de ser parte del ámbito de lo privado y aún de lo íntimo, situándose en una suerte de interregno de poder para quienes controlan la World Wide Web.

Hoy sabemos que los datos personales, imágenes e informaciones de todo tipo son conocidas y almacenadas sistemáticamente por los servidores a los que como usuarios tenemos acceso. Nuestros mensajes de correo electrónico no viajan directamente al destinatario, sino que pasan por un sinnúmero de ordenadores antes de arribar a la cuenta de destino, dejando una huella en cada uno de ellos. Redes sociales como Facebook disponen de cláusulas sobre el uso de los datos que le permiten disponer de todo lo que los usuarios almacenan en su cuenta y Google, el más exitoso de los buscadores, cuenta con tecnologías que le permiten registrar cada página visitada por cada uno de los usuarios, lo cual se traduce en el conocimiento de sus preferencias, intereses y deseos y, lo que es más importante, en la capacidad de dirigir sus búsquedas. Todo ello sin contar con el uso indebido que las mencionadas empresas pueden hacer con los datos de los usuarios, al destinarlos sin autorización para campañas de mercadeo o, peor aún, al compartir sus bases de datos con agencias de inteligencia. 


\section{Corolario}

Este trabajo realizó un análisis de las implicaciones que Internet ha tenido sobre lo público, la esfera pública y la opinión pública. Aunque se trata de un medio de comunicación con creciente influencia en la formación de la opinión pública, el grado de incidencia que pueda tener debe ponderarse en comparación con el funcionamiento tradicional de la esfera pública. En este sentido, se trató de evitar un "determinismo tecnológico" que por enfatizar en la novedad y en las rupturas dejara de enfocarse en las continuidades. Ello implicó una reconstrucción de los conceptos de lo público, la esfera pública y la opinión pública.

Lo público está inextricablemente relacionado con lo que se considera visible, admisible y enunciable, por contraposición a lo que no reviste esas características y, por consiguiente, se reserva al ámbito de lo privado. La esfera pública, por su parte, hace referencia a un espacio institucionalizado de participación ciudadana que tiene como fin formar la opinión pública, entendida como la definición del interés común, que no es consensual sino que está caracterizada por la competencia y el conflicto entre distintos intereses privados en discusión.

Aunque el espacio virtual de Internet hace posible una comunicación más horizontal y una mayor igualdad entre las personas conectadas, no ha producido un cambio sustancial en la forma como desde los albores de la modernidad ha funcionado la esfera pública. Los mecanismos que permiten esa comunicación horizontal y esa mayor igualdad en el mundo virtual, se ven contrarrestados por las prácticas de conflicto y competencia desiguales que priman en la definición de las audiencias y el posicionamiento de "tendencias".

En lo que se refiere a la accesibilidad, el ciberespacio ofrece oportunidades impensadas de intervención en la esfera pública. No obstante, depende, en última instancia, del grado de conectividad, por lo que en la práctica mantiene las restricciones y exclusiones que han caracterizado el funcionamiento de la esfera pública. En cuanto a la deliberación, el Internet posibilita una comunicación más dialógica que otros medios de comunicación y puede ser aprovechado por contrapúblicos para poner a circular opiniones no hegemónicas. Sin embargo, no implica un avance sustancial respecto de las lógicas de producción de la opinión pública que predominan en el "mundo real", como la orientación de la opinión mediante mecanismos de mercadeo. Con todo, Internet ha llegado a amenazar la esfera de lo privado y de lo íntimo. Ello no se ha 
traducido, empero, en una ampliación del espacio público. En otras palabras, aquello que ha dejado de ser privado, datos personales, imágenes, informaciones, no ha transitado hacia el espacio de lo privado sino hacia el poder de quienes tienen el poder de controlar la World Wide Web.

\section{Bibliografía}

ARENDT, H. (1996) La condición humana. Barcelona: Paidós.

BOBBIO, N. (2006) Estado, gobierno y sociedad. México: FCE.

CASTELLS, M. (2001) La galaxia internet. Madrid: Areté.

FRASER, N. (1997) "Pensando de nuevo la esfera pública. Una contribución a la crítica de las democracias existentes", en Iustitia Interrupta. Bogotá: Siglo del HombreUniversidad de los Andes.

HABERMAS J. (1982) Historia y crítica de la opinión pública: la transformación estructural de la vida pública. Barcelona: Gustavo Gili.

LOZANO, A. (2005) "Algunos problemas sobre lo público", en: Debates sobre lo público. Bogotá: ESAP-Universidad Nacional de Colombia, pp. 30-56.

MARSHALL, H. (1997) [1950] “Ciudadanía y clase social”, en: Revista española de investigaciones sociológicas, 79.

MARTÍN-BARBERO, J. (1988) De los medios a las mediaciones. Barcelona, Gustavo Gili.

NEGRI T. Y HARDT M. (2001) Imperio. Bogotá: Desde Abajo.

RABOTNIKOF, N. (1997) "El espacio público: caracterizaciones teóricas y expectativas políticas". Filosofia Política I. Ideas políticas y movimientos sociales. Ed. Fernando Quesada. Madrid: Trotta, pp. 135-151.

SÁNCHEZ MUÑOZ, C. (2003) Hannah Arendt. El espacio de la política. Madrid: Centro de Estudios Políticos y Constitucionales. 
TILLY Ch. Y WOOD L. (2008) Los movimientos sociales 1778-2008. De sus origenes a Facebook. Barelona: Crítica.

VARELA E. (2005) Desafios del interés público. Identidades y diferencias entre lo público y lo privado. Cali: Universidad

WILLS M. (2005) "Democracia, públicos oficiales y contrapúblicos", en Debates sobre lo público. Bogotá: ESAP-Universidad Nacional de Colombia 
